\title{
Fatty Acid Esters in Europe: Market Trends and Technological Perspectives
}

\author{
M. Bloch'1, L. Bournay ${ }^{2}$, D. Casanave', J.A. Chodorge' ', V. Coupard², \\ G. Hillion ${ }^{3}$ and D. Lorne ${ }^{3}$ \\ 1 Axens, 89 boulevard Franklin Roosevelt, BP 50802, 92508 Rueil-Malmaison - France \\ 2 Institut français du pétrole, IFP-Lyon, Autoroute A7, BP 3, 69390 Vernaison Cedex - France \\ 3 Institut français du pétrole, IFP, 1-4 avenue de Bois-Préau, 92000 Rueil-Malmaison - France \\ e-mail: michel.bloch@axens.net - laurent.bournay@ifp.fr - dominique.casanave@ifp.fr - jean-alain.chodorge@axens.net \\ vincent.coupard@iff.fr - gerard.hillion@ifp.fr - daphne.lorne@ifp.fr
}

\begin{abstract}
Résumé - Ester d'acide gras en Europe : tendances de marché et perspectives technologiques En raison d'un système initialement fortement incitatif mis en place par l'Union Européenne, la production d'ester d'acide gras (EAG) commence à s'étendre et à gagner le monde. Un examen approfondi du système complexe de compensations financières proposé par les états membres et une mise à jour annoncée en matière d'augmentation des capacités de production de biodiesel peuvent permettre de dégager les facteurs de succès de cette expansion aussi brutale que soudaine. Ce tissu de données économiques et législatives démontre l'existence de solutions technologiques alternatives pertinentes permettant de pérenniser ce succès.

En effet, cette hausse de la production attendue d'EAG engage de plus en plus à se soucier de l'optimisation et de la rationalisation des unités de forte capacité pour qu'elles utilisent la meilleure technologie disponible visant des rendements élevés tout en veillant au respect de l'environnement, particulièrement au regard de la co-production de déchets.

Cet article présente une technologie alternative permettant d'apporter une réponse originale à ce problème, technologie mettant en œuvre un catalyseur hétérogène pour la transesterification des huiles végétales. Ce procédé s'appuie sur la réaction de méthanolyse des huiles végétales, réaction réalisée sur deux réacteurs successifs en lit fixe, suivie par des étapes de séparation du méthanol en excès et de la glycérine de l'ester méthylique formé.

Ce procédé ne requiert ni section de récupération du catalyseur, ni traitement de rejet aqueux. Il montre un haut rendement en ester méthylique, proche de la limite thermodynamique. La conversion peut également être ajustée sans avoir recours à une consommation de catalyseur complémentaire. La glycérine co-produite possède directement une pureté de $98 \%$ et est exempte de contaminants sous forme de sels ou de savons. L'absence de rejets et la qualité des produits fait que ce procédé est, au-delà de l'aspect 'environmentally friendly' inhérent à ses produits, un «procédé vert».
\end{abstract}

Abstract - Fatty Acid Esters in Europe: Market Trends and Technological Perspectives - Based on strong governmental incentives, biodiesel from transesterification of Fatty Acids (FAE) production is rapidly increasing mainly in Europe and is starting to expand worldwide. A closer look at the complex European incentives scheme and an update of the planned FAE capacity expansion helps to explain the key economic factors in this sharp raise in FAE activity. Based on this economic background, key factors for FAE technology selection will be explored to demonstrate alternatives for biofuels production. 
Increasing biodiesel consumption in a sustainable way requires optimizing production processes compatible with high production capacities, high yields and low environmental impact, especially regarding wastes streams.

This paper highlights a commercially proven technology available for meeting these challenges, focusing on a new continuous FAE production process where the transesterification reaction is promoted by a heterogeneous catalyst. This process employs methanolysis of vegetable oils by passing the reactants through two consecutive fixed-bed reactors followed by methanol and glycerin separation stages.

The Axens process requires neither catalyst recovery nor aqueous treatment. It achieves very high methyl esters yields with a high purity glycerin byproduct. At least $98 \%$ purity glycerin is directly recovered in the total absence of any mineral (salts) contaminants thereby offering an alternative for a real "Green Process".

\section{INTRODUCTION}

Biofuels, fuels from a renewable vegetal origin, have gained importance since the first oil crisis and are seen as a good solution to lower the dependence on fossil fuels, as well as providing a blending component to limit exhaust pollutants of transportation fuels. Until recently fossil oil price remained too low for these biofuels to be competitive. However public opinion, growing environmental concern, a focus on $\mathrm{CO}_{2}$ emissions, and recently increasing fossil oil price have lead the European Union to reopen the biofuel file and to actively promote the development of biofuels.

As European liquid fuels consumption is mainly diesel oriented (Fig. 1). The biodiesel market was the first to benefit from technology developed in the late 80 's. The total amount of biodiesel produced increased to 3.6 Million tons in 2005, $90 \%$ of European origin and 5.4 Million tons in 2006, The European share lowering to $70 \%$ (Fig. 2) as biodiesel production started to expand worldwide, principally in the US and Brazil.
As a leader in this field, European biodiesel development is probably a model for a worldwide future biodiesel expansion. Although economic and local regulations are needed to make biodiesel fuel competitive toward fossil fuel, technological advances will give biodiesel a long term position in the diesel market.

\section{EUROPEAN BIOFUELS REGULATION AND CAPACITY EXPANSION KALEIDOSCOPE}

\subsection{Regulation Background}

\subsubsection{One Common European Biofuels Directive}

The European Union 2003 directive on biofuels (EC 2003/30) established the initial objective of substituting $2 \%$ of fuel by fuel from renewable origin by the end of 2005 . The second goal was set to reach a $5.75 \%$ by 2010 . A target of

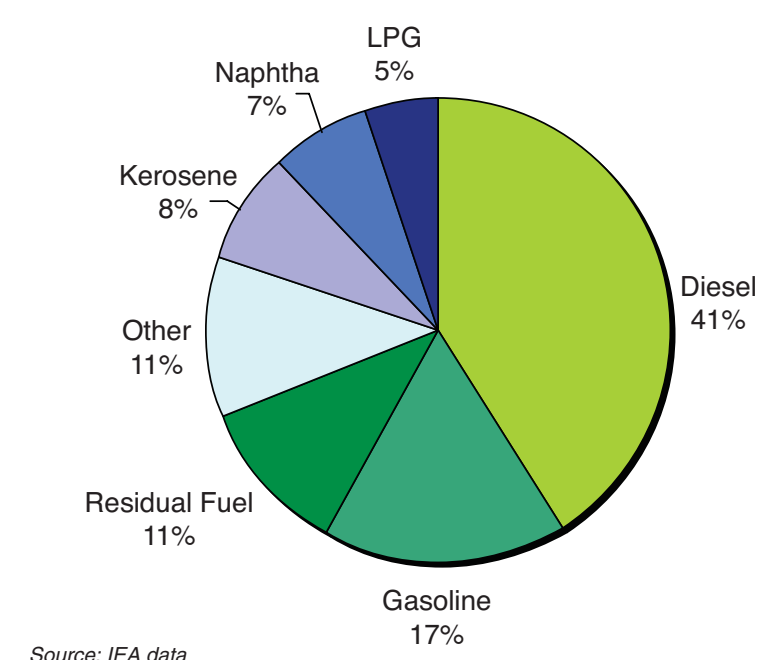

Figure 1

Total Western Europe refining product demand in 2006.

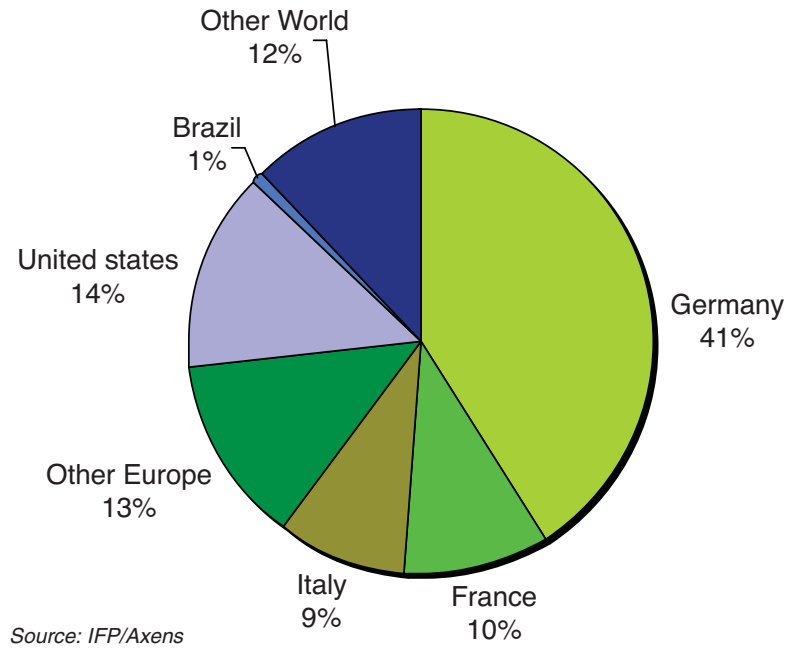

Figure 2

World 2006 biodiesel production split. 
$10 \%$ by 2020 was announced during last European board meeting in March 2007 as a possibility.

All these numbers are expressed in calorific value of fuel. As most biofuels contain oxygen their calorific values is lower than those of fossil fuels and vary [7] to a slight extent depending upon the feedstock.

Based upon the EU Commission's recommended conversion rate of 1 ton biodiesel $($ FAME) $=0.86$ TOE (Ton Oil Equivalent), a $6.69 \mathrm{wt} \%$ blending rate of FAME will be required to meet the $5.75 \%$ target.

\subsubsection{Local Adjustment of Directive}

The European Union 2003 directive has been applied differently by each member state depending on political background. Each different state is now proposing both revised targets and local policy developments in order to achieve the best incentives to meet their objectives.

Germany has always been on the forefront of biodiesel production. Policy has initially promoted biodiesel by a full Mineral Oil tax exemption. This system was recently changed due to unbalanced growth and overcompensation. Since January 1st, 2007, a mandatory level of $4.4 \%$ in terms of calorific value has been set as the minimal level of biodiesel incorporation in fossil diesel. In order to promote domestic production, the Mineral Oil tax exemption for B5 has been removed, but only a temporary partial loss of this exemption for B100 is now in force. In addition, high penalty fees are imposed on fuel suppliers who cannot achieve their mandatory implementation.

France set more ambitious, higher targets of $5.75 \%$ of fuel calorific value by $2008,7 \%$ by $2010,8 \%$ by 2012 and $10 \%$ by 2015 . [12]. A tax exemption model is used to favor introduction of biofuels in fossil fuel. For biodiesel, a reduction of internal tax on petroleum products (TIPP) is used to make it attractive. Another tax for fuel, based on pollutant activities (TGAP) will gradually help meet the European target of $5.75 \%$ biodiesel by 2010 , by penalizing all fuel not including the required amount of biofuel on the market in the country.

Other European countries do not openly disclose promotional measures or tax exemptions for further increasing biodiesel activities. Mandatory incorporation levels or Ecotax exemption however give two kinds of legislative tools to enforce European law. This kind of financial biofuel preference with the historically high prices of crude are the main factors for the biodiesel capacity expansion observed worldwide.

\subsection{European Biodiesel Capacity Expansion Perspectives}

\subsubsection{Announced European Capacity Expansion Plan}

Initial 2005 figures show a limited 4 Mt of biodiesel capacity was build (with 3.2 Mt produced) in EU-25, mostly in Germany (Fig. 3). Biodiesel remains the main biofuel produced, by more than $70 \%$ [16]. Total biofuels production in 2005 accounts for $1 \%$ on a calorific value of the overall transportation fuel, only half of the initial European directive target.

Based upon projects announced, further increase of overall FAE capacity is expected in Europe. Initial 2005 installed capacity level is expected to be multiplied by 6 (Fig. 4) by the end of 2008. This is based on FAE companies press announcements so this figure is an optimistic view of the future installed FAE capacity. However, the trend is real and a capacity shift for edible oil methanolysis units is underway.

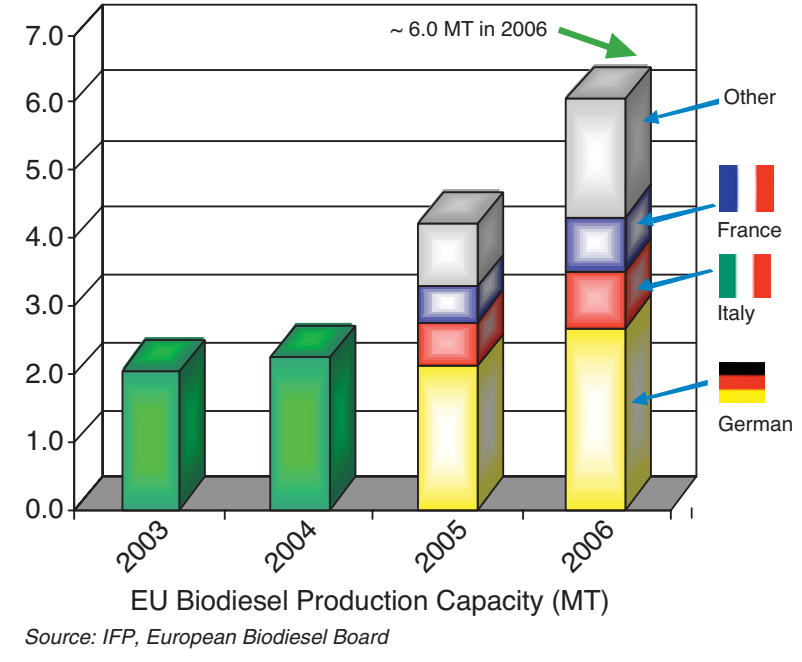

Figure 3

EU biodiesel production capacity 2003-2006.

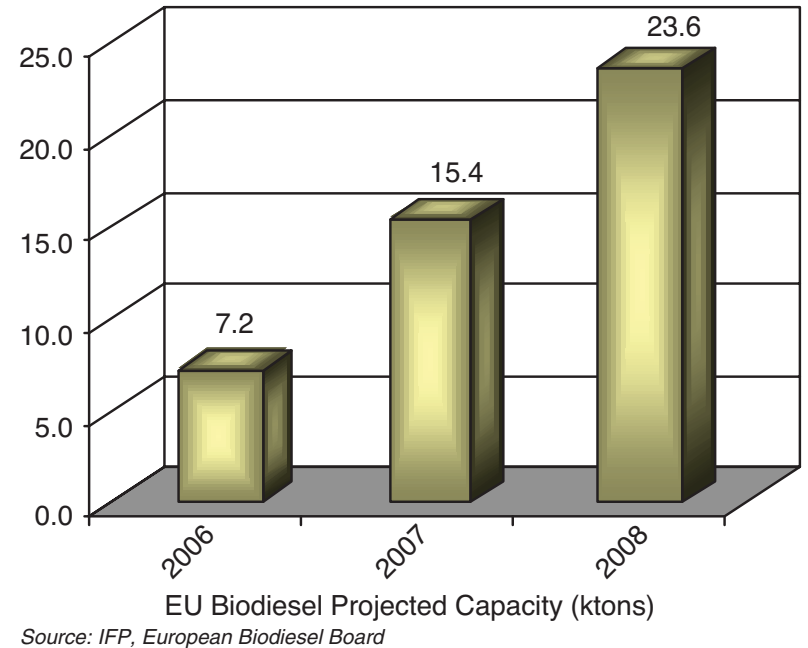

Figure 4

Projected capacity expansion 2006-2008. 


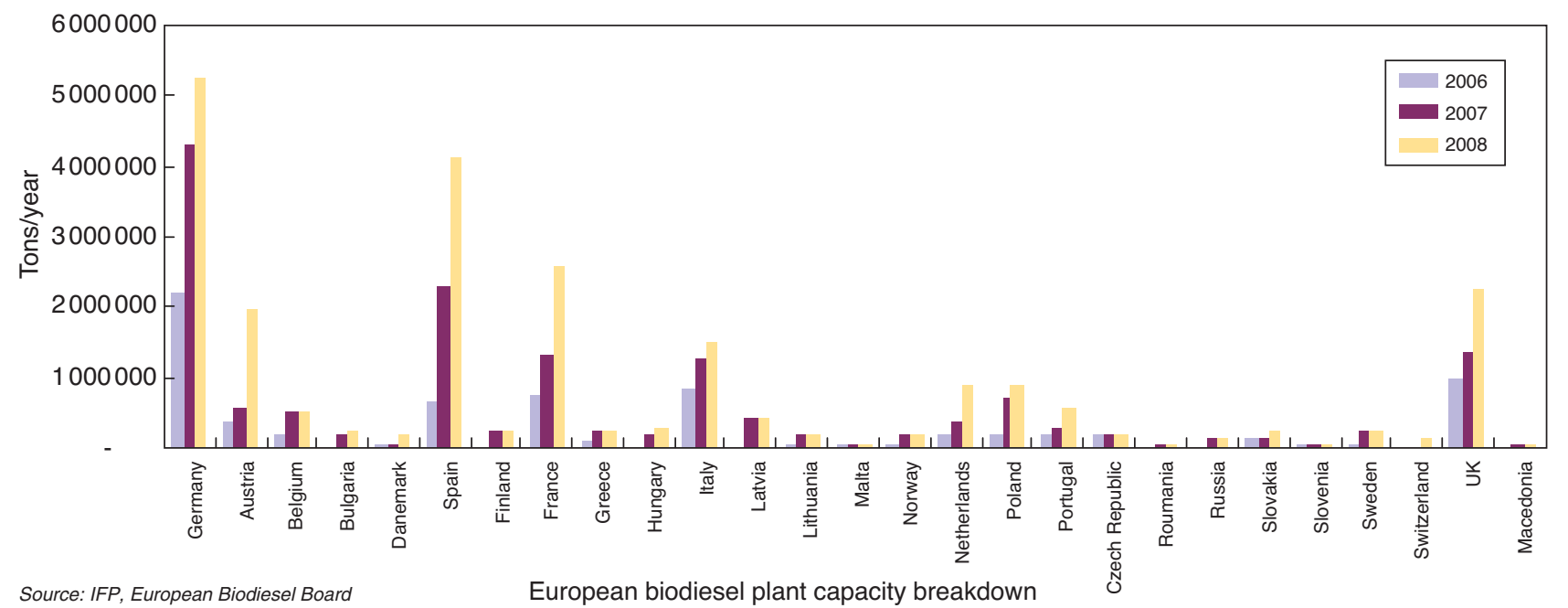

Figure 5

2006-2008 European capacity breakdown based on announcements.

\subsubsection{Distribution of Expansion Plans}

As a whole, the proposed capacity expansion is not distributed equally over all EU-25 members. Spain and Austria have made big announcements for 2008 that need to be fulfilled (Fig. 5). It is however noticeable that countries investing in FAE are mainly countries with biodiesel production history. Both Germany and France, where mandatory blending or Ecotax exemption system for biodiesel production have been described before, have plans for large capacity expansions.

If we look into more detail in France, based on the expected diesel consumption in the country, FAME implementation has to reach $2286000 \mathrm{t}$ in 2008 and $2905000 \mathrm{t}$ by $2010[12,13]$ to comply with the European directive on biofuels. The installed capacity level by the end of 2008 will be compatible to reach 2010 objectives provided that additional capacity expansions are done in 2009-2010. Feed availability may be the limit for reaching these objectives but home grown seeds are probably not enough and additional material import will be needed [13].

In Germany, based upon a minimum $4.4 \%$ incorporation level, expected diesel consumption in 2010 [14] will require $1491000 \mathrm{t}$ of FAE. This production level which was already achieved in early 2007. As FAE capacity is expected to further increase, Germany may be in a situation of FAE exporter inside Europe to help other member state to comply with the European directive, if policy and price scenario makes this kind of operation attractive.

\subsubsection{Plant Capacity Shift}

If we look into more detail on the specific announcements by European members, it becomes clear that the minimum installed capacity for new FAE plants has increased, whatever the geographical location. In the beginning of FAE activity, small plants of less than $10000 \mathrm{t} / \mathrm{y}$ of FAME capacity used to be erected. Now the minimal economic size seems to be above $150000 \mathrm{t} / \mathrm{y}$ (Fig. 6). Recent projects have announced plant capacities of 200000 and $250000 \mathrm{t} / \mathrm{y}$.

FAE is now entering a second phase were rationalization of the mass production is taking place. This may force owners of plants utilizing older technology to shut down the small capacity units not well suited on the production cost side.

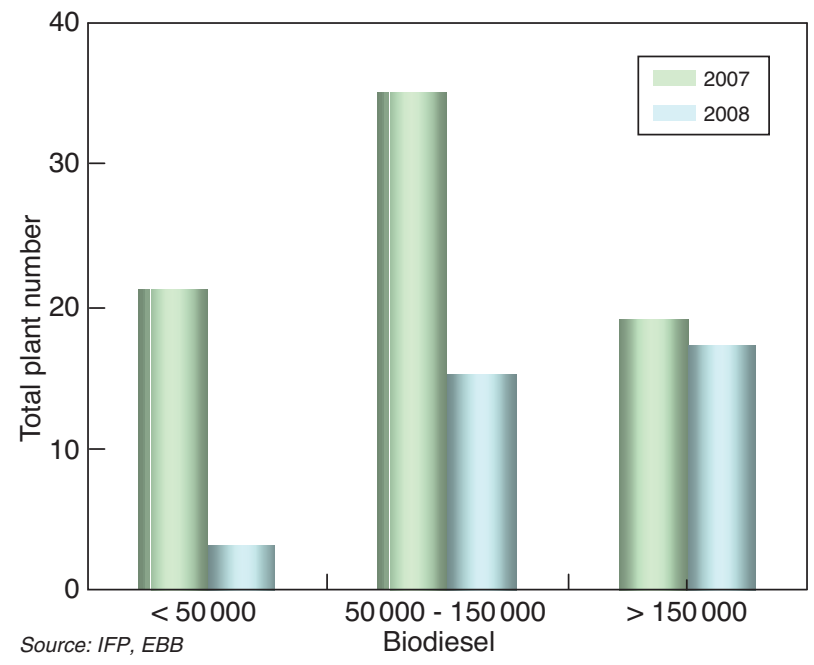

Figure 6

New Plant capacity shift. 


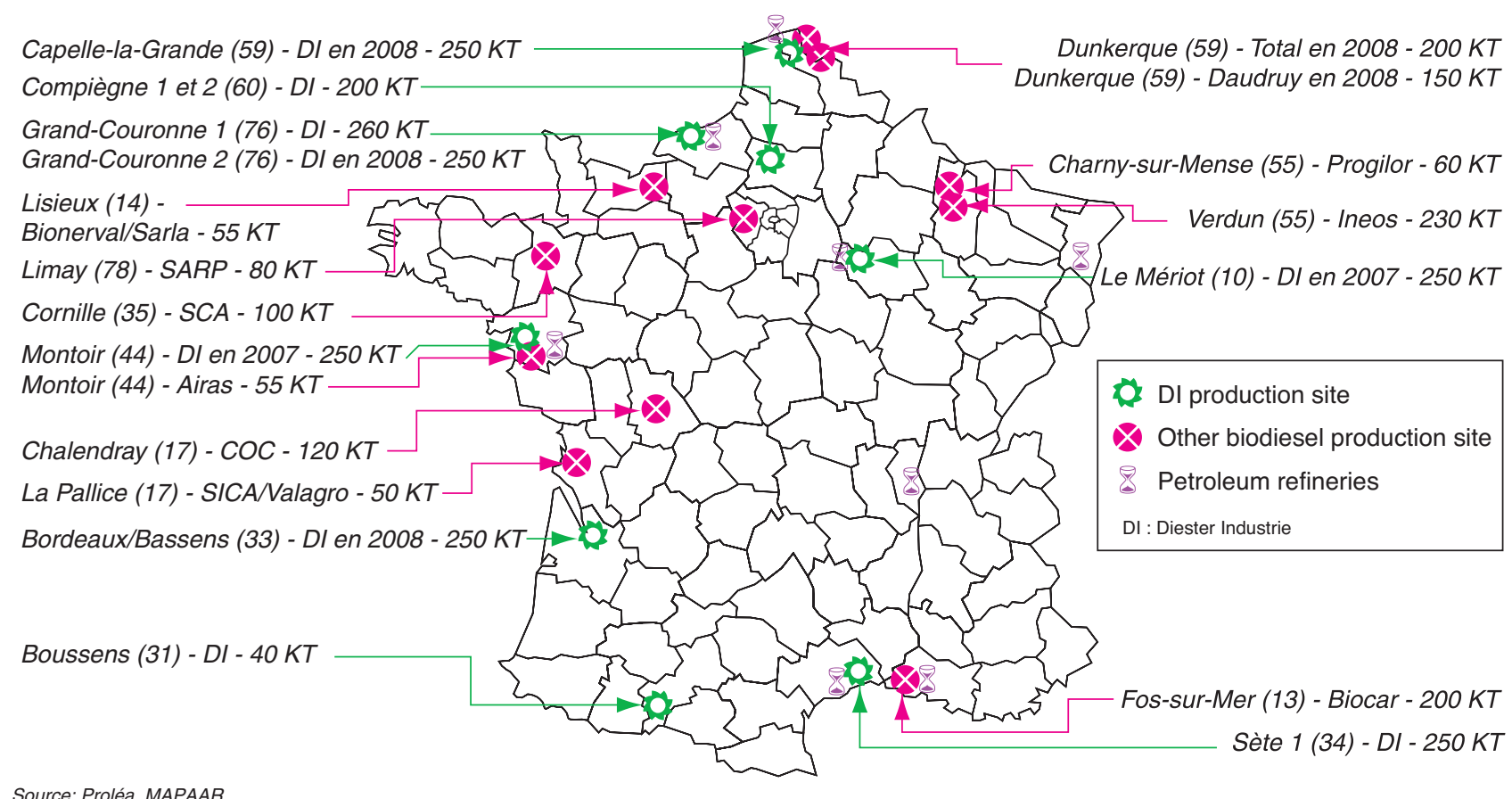

Source: Proléa, MAPAAR

Panorama IFP - $1^{\text {er }}$ février 2007

Figure 7

France simplified FAE map.

\subsubsection{France Close Up}

A closer look at France's specific case (Fig. 7), were Diester Industrie is the major player, shows that most of the FAE plants are erected close to big distribution spots in the biggest agricultural area of France. Logistic concerns play a crucial role in the final site choice. All large existing sites are also located near a harbor for import/export of oil by sea to help solve the feed vegetable oil availability issue.

FAE facilities are also generally located in the vicinity of French petroleum refineries. This proximity allows shorter transportation time, reducing the impact of the lower oxidation stability of these fuels. FAE is blended with fossil fuel afterward in the refinery and distributed through the mineral oil company distribution network.

\subsection{European Biofuel Market: Fulfilling the Target?}

As a conclusion, comparative examination of capacity expansion to European directive targets (Fig. 8), it appears that Europe will likely not reach as a whole the global 5.75 target by 2010 , even with the huge capacity expansion announcements unless another biodiesel source not coming from FAE fills in the remaining gap. Import of FAE from outside of Europe will have to take place if the current mainly tax incentive policy evolves in a more mandatory regulation.
Aside from political and financial aspects, which are the real sting to this FAE revolution, logistical and technical aspects also play a big role. Feed availability, competition with food and feed/final product transportation questions have to be addressed to know were FAE can be produced at optimal cost and minimal environmental impact. Production cost will also impact on final product quality and yield. These are key factors regarding FAE activity. The choice of FAE plant technology has direct or indirect impact on all these key factors and must be thoroughly studied to maximize long term success, even with a possibility of political or financial changes.

\section{TECHNOLOGICAL ASPECTS OF FAE PRODUCTION}

\subsection{Methyl Esters}

The direct use of vegetable oils in diesel engines is well documented $[10,11]$ and has been proposed since the origin of the diesel engine. The direct use of vegetable oil has limited application as it leads to coke deposit formation in the combustion chamber resulting in reduced engine performance as well as a higher emission level [9]. These detrimental effects are, especially evident in today's most advanced direct injection engines. 


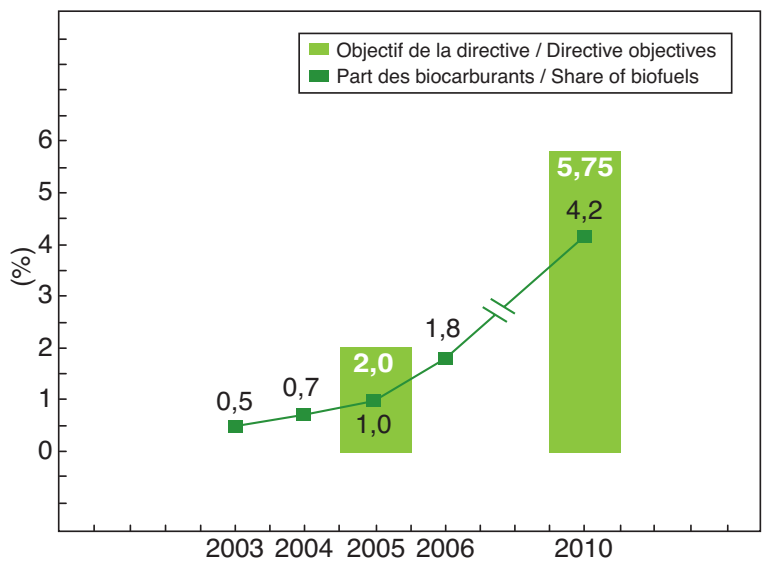

Source: EurObserver ER 2007 No. 179, May 2007

Figure 8

Comparison of the current trend with the directive on biofuels objectives [16].

If we try to identify the oil component properties which limit its usage directly as fuel or a blending agent with fossil diesel, the main elements of the list will be: $[9,7]$,

- Viscosity of oil, generally more than $30 \mathrm{~mm}^{2} / \mathrm{s} @ 30^{\circ} \mathrm{C}$, 10 time a regular diesel value, making blending and injection into the engine more difficult;

- Moderate or low Cetane Number (39-44 for rapeseed);

- CFPP (oil dependant, $-5^{\circ} \mathrm{C}$ to $-15^{\circ} \mathrm{C}$ for rapeseed and more than $10^{\circ} \mathrm{C}$ for palm oil) compared to -20 for mineral diesel.

The use of the methyl ester of vegetable oils has been proposed as early as 1983 by Guibet et al. [1] and one of the first industrial units was started in France near Compiègne based on an IFP design in 1992 with a 20000 t/y capacity. The use of methyl ester instead of vegetable oil has the advantage of changing the viscosity and cetane number of the biomass fuel to make it much closer to that of fossil diesel fuel. The blend with fossil diesel becomes much more easy and the product more stable. Methyl esters can be used both as a diesel alternative (B100) or as a diesel blending component (B5-B7).

Methyl esters are produced from vegetable oils through a transesterification reaction. The transesterification of triglycerides to Fatty Acid Methyl Esters (FAME) with methanol is a reversible and catalyzed reaction, as illustrated in Figure 9 (Overall reaction scheme for transesterification of vegetable oil).

An excess of methanol is required to obtain a high degree of conversion.

Vegetable oils needed for transesterification may be of different biological origin. The choice of oil depends on geographical location of the crushing site, as well as on local policy. In Europe rapeseed oil is predominant, in the US and South America soybean oil is the most common. In South East Asia palm oil is used as the primary oil source for the FAE industry. After crushing and refining to remove unwanted contaminants, oil can be sent to a FAE transformation site. A typical mass balance yield for rapeseed oil is given in Figure 10 (Simplified FAE plant mass balance - rapeseed case).

FAE production expansion plans involve a sharp increase of all chain co-products, mainly glycerin, fatty acids and crushing residue. The outlet for the crush residue has traditionally been cattle feed, and indeed the main reason for the seed production. As production increases and for some seeds with higher oil content, the crush residue may become a byproduct for use in animal feed, power generation, or biomass conversion.

\subsection{Methyl Esters of Vegetable Oils Through Homogeneous Process}

\subsubsection{Homogeneous Process Description}

The conventional industrial FAE processes are based on homogeneous alkaline catalysts. Sodium hydroxide or sodium methylate are the most often used catalyst in industrial processes (the potassium analogues are also alternatives). This

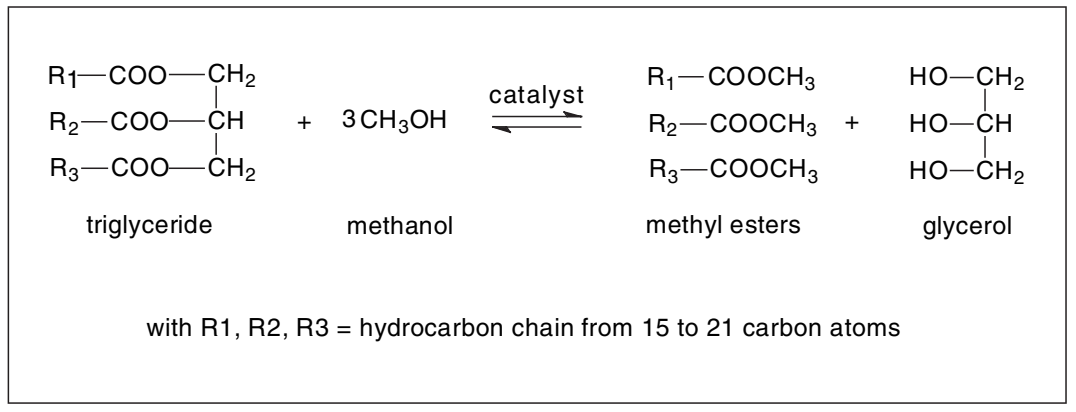

Figure 9

Overall reaction scheme for transesterification of vegetable oil. 


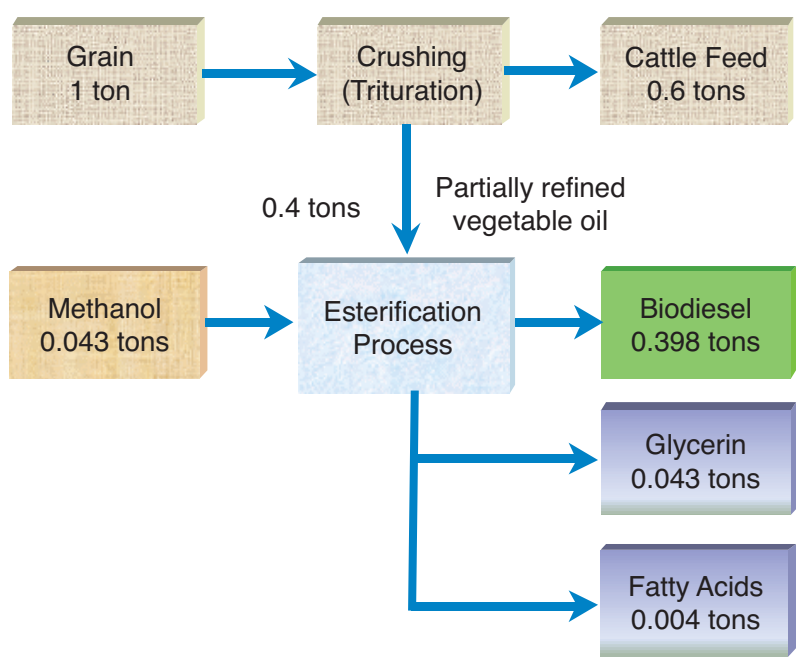

Figure 10

Simplified FAE plant mass balance (rapeseed case).

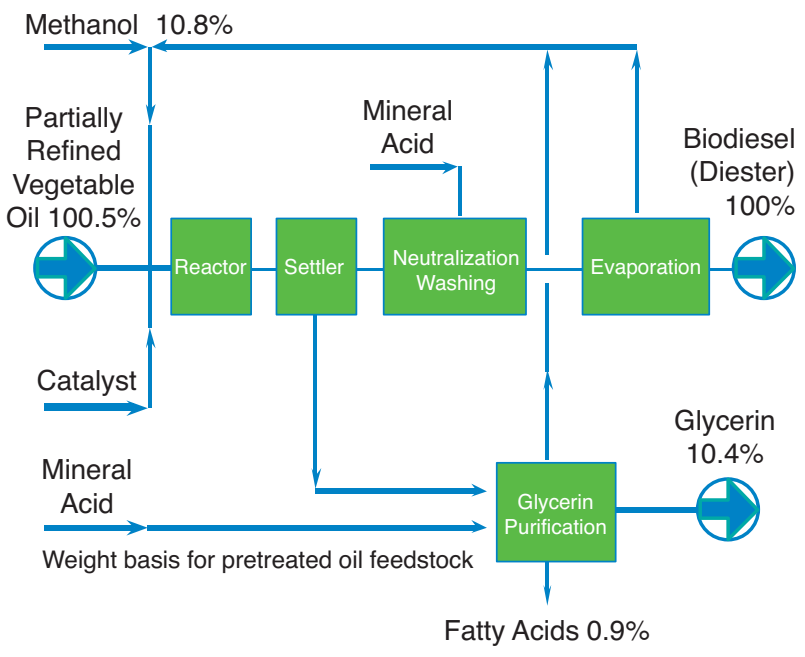

Figure 11

Simplifed view of homogeneous transesterification plant. catalyst is dissolved in the methanol make up to the unit or injected directly if in liquid form (Sodium methylate for example). Catalyst feed can be adjusted to match the required product conversion (i.e. FAE final quality). Catalyst feed is generally used in excess to ensure the mandatory conversion level. Optimum catalyst concentration level ranges from 0.5 to $1.0 \mathrm{wt} \%$, based on vegetable oil feed. Free fatty acids in the reaction mixture can partly be compensated by the addition of excess catalyst. However a higher catalyst concentration leads to a higher solubility of methyl ester in the glycerol phase, yielding an increase in the settling time and requiring an adaptation of the glycerin purification step.

The removal of homogeneous catalyst from the reactor effluent requires further downstream operations, that are illustrated in Figure 11 (Simplifed view of homogeneous transesterification plant).

Homogeneous reaction conditions allow a natural continuous settling of glycerin from the reacting mixture enabling a displacement of the reaction equilibrium. Water added through mineral injection, catalyst, vegetable oil, methanol acts as an inhibitor for the transesterification reaction and must be removed from the system to avoid accumulation, and catalyst activity loss. Water outlet is done through slip side stream or in the final glycerin, hereby lowering its purity.

The crude ester product is purified by a washing step in order to remove the last traces of catalyst $(\mathrm{Na}+\mathrm{K}$ content in the final ester needs to be lower than $5 \mathrm{ppm}$ in order to respect EN14214). In some cases, a third reactor using acidic water can be used to polish FAE a in respect to alkaline and glycerin content. All of the settling and neutralizing effluent are sent to glycerin purification section for further treatment. The FAME residual methanol \& water content is evaporated and methanol is then recycled into the process.
The major part of the catalyst is recovered after the transesterification reaction as sodium glycerate, sodium methylate and sodium soaps in the glycerol phase. An acidic neutralization step with, for example, aqueous hydrochloric acid (sulfuric and phosphoric acid are also alternatives) is required for this operation: sodium soaps are thus converted into free fatty acids that can be removed from glycerin by a simple settling. In this case, glycerin is obtained as an aqueous solution containing sodium chloride. Depending on the process, the final glycerin purity is about $80 \%$. Impurities are salts and water.

When sodium hydroxide is used as catalyst, side reactions forming sodium soaps generally occur. This type of reaction is also observed when sodium methylate is employed and traces of water are present. The sodium soaps are soluble in the glycerol phase and are recovered under their fatty acids form after acidic neutralization and settling. The loss of esters converted to fatty acids can be as high as $1 \%$ of the FAE production. The FAME yields obtained can vary from 98.5 up to 99.5 (wt \%), depending on the feed quality and the type of catalyst utilized.

\subsubsection{Industrial Experience}

Commercial industrial processes can be operated in a batch mode or in a continuous mode. In the ESTERFIP batch process (IFP/Axens license) (Picture 1), the transesterification reaction occurs in a single stirred tank reactor. Refer to Figure 12 (EsterFip Homogeneous process for FAME production).

Reaction is done batchwise, minimizing the equipment needed and ensuring a constant control of the conversion of the oil to FAME. Final product treatment (FAME and glycerin) is done in a continuous mode. 6 plants of this type have been built since 1992 for a total of $1.2 \mathrm{Mt} /$ year of capacity. 


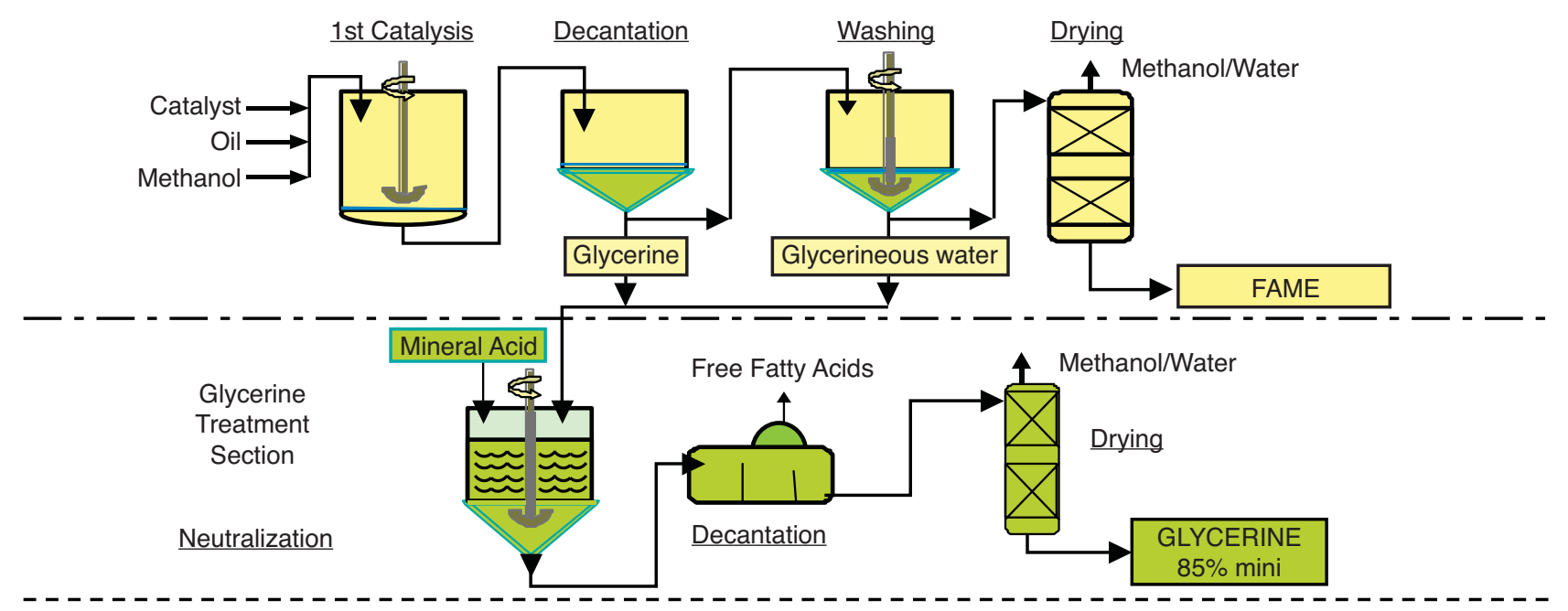

Figure 12

EsterFip Homogeneous process for FAME production.

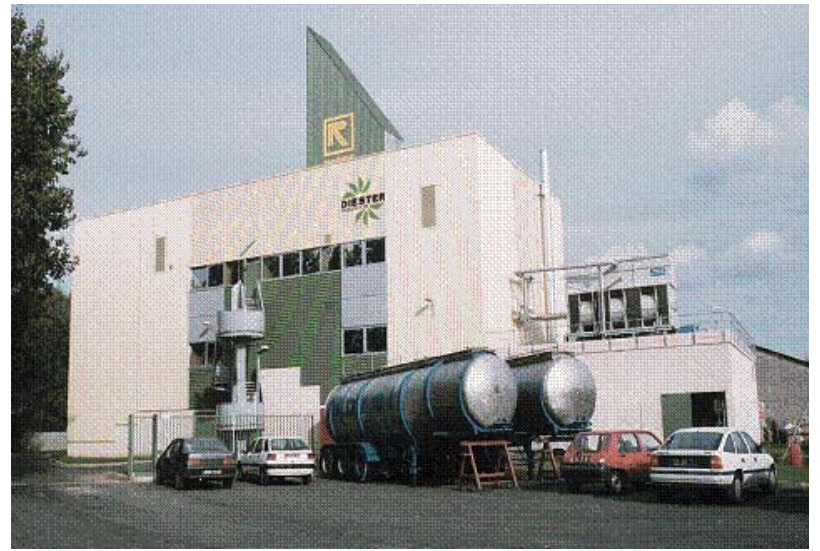

Picture 1

EsterFip Compiègne plant.

Continuous transesterification processes include the Ballestra, the Connemann CD and Lurgi PSI processes. These continuous process require two or three reactors operated in series. After each step of catalysis reaction, glycerol is removed either by gravity or centrifugation [2]. A key point for these processes is the final methyl ester washing. This final washing step is to remove remaining glycerin, water, methanol and catalysts. This wash is done in some cases by using a counter current final water wash tower. Basic salts coming from both the glycerin treatment and water wash effluent streams are neutralized using strong acidic compound.

For both continuous and batch transesterification processes, around $4 \mathrm{~kg}$ of salts is co-produced in the glycerin phase per each ton of oil processed. This amount of salt is left to be treated by glycerin end users: in all case, for batch homogeneous FAE processes, the neutralization step leads to the formation of salts, carried in the glycerin phase, final disposal. Glycerin and free fatty acids from homogeneous FAE processes can be considered as waste streams.

\subsubsection{Homogeneous Process Strengths and Weaknesses}

These processes are satisfactory on several aspects:

- very active catalyst;

- good thermal efficiency, low energy consumption;

- range of capacity (10 000-250 $000 \mathrm{t} /$ year);

- product has been blended up to $30 \mathrm{wt} \%$ with diesel for captive fleet experience like urban buses, and introduction in regular diesel has been done on regular basis at $5 \%$ level.

The main difficulties are the handling of strong acids and base chemicals and the production of impure glycerol (containing the salt resulting from the neutralization of the soluble catalyst by a mineral acid, either hydrochloric or sulfuric acid), in large amounts as compared to the existing markets of glycerol.

The main impurities in the glycerin by-product are water, salts $\left(\mathrm{NaCl}, \mathrm{Na}_{2} \mathrm{SO}_{4}, \mathrm{KCl}\right.$... depending on the base used as catalyst and on the acid used for catalyst neutralization), and organic compounds such as esters and soaps. Possible uses of this crude glycerin are limited: it can be burned in furnaces, even though glycerin combustion may induce technical difficulties due to its high flash point and the presence of salts) or it can be incorporated into animal feed [3].

The crude glycerol can be refined in order to obtain the USP grade, used in pharmaceuticals, cosmetics and food applications. This crude glycerin product is often colored, brown and dark and must be treated by multiple distillation 


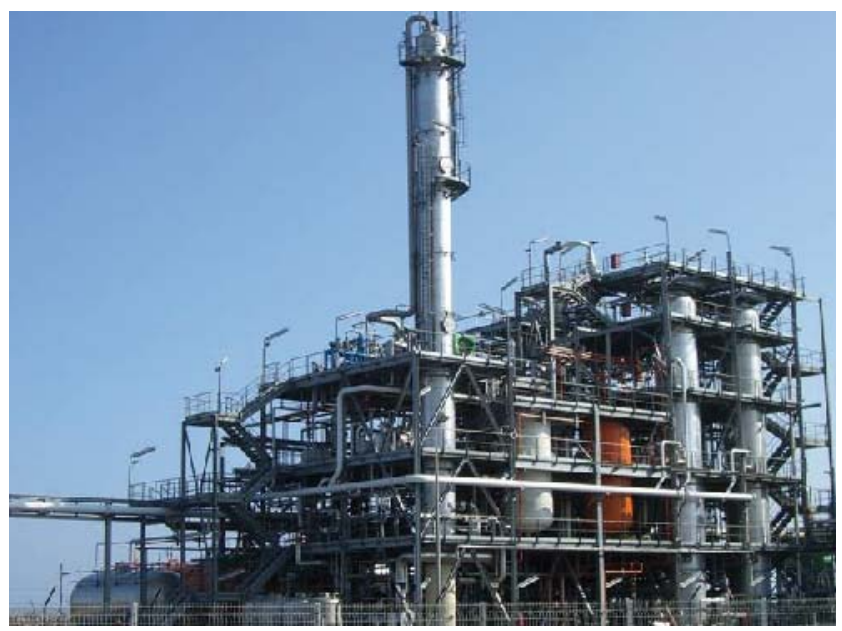

Picture 2

Diester Industrie EsterFip-H plant, Sète, France.

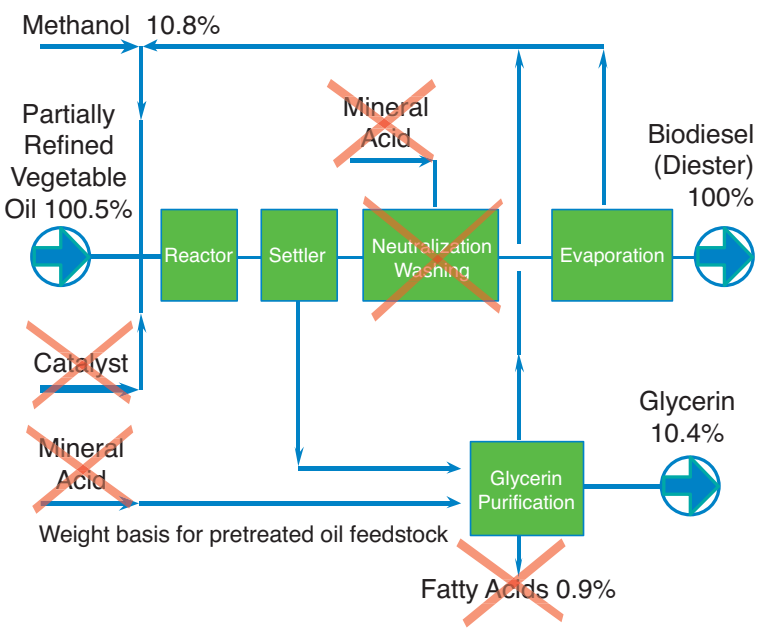

Figure 13

Simplified schematics of EsterFip-H Process. and discoloration techniques to reach pharmacopoeia compliance, enabling its usage in solvent, food, cosmetics, and the pharmaceutical industry.

The first step is to get rid of the neutralization salt. The purification scheme is rather complex and costly, both in terms of investment and operating cost, i.e. energy needed to do this purification, especially if distillation is required. Furthermore, the reaction produces wastes (mainly sodium salts polluted by organic compounds) that have to be disposed of.

Massive building of homogeneous FAE plants will yield a sharp increase in FAE wastes, which will need a remedial solution. Achieving wide diffusion of green fuels using this high environmental impact process does not seem to be the most viable solution.

\subsection{Improving the Transesterification Route}

\subsubsection{Heterogeneous Catalysis}

\section{Process Description}

The classical route decribed in Section 2.2 involves very active soluble catalysts, with the major drawback of a difficult purification of the glycerol produced, as discussed above. A simple way to avoid the problem is to turn to heterogeneous catalysis. Such a process has been developed by IFP and is being commercialized by Axens [4] under the trade name Esterfip- $H^{\mathrm{TM}}$. The first industrial unit was started in 2006, at Sète (Picture 2), in the south of France.

In this new continuous process, the transesterification reaction is promoted by a completely heterogeneous catalyst. This catalyst consists of a mixed oxide which promotes the transesterification reaction without catalyst loss [5].

The use of a solid catalyst completely removes the use of external catalyst addition, catalyst neutralization step and water washing step (Fig. 13). Thus, the global water content of all products made with this process will be drastically lower. The residual fatty acids entering the process are esterified to FAME, thus increasing the overall yield of the process. Esterification of fatty acids yield some water as a reaction product, therefore, overall fatty acid content entering the process must be properly monitored to limit water formation.

The desired chemical conversion, required to produce FAE on specifications, is reached with two successive stages of reaction and glycerin separation (Fig. 14) in order to shift the equilibrium of methanolysis. The catalyst section includes two fixed bed reactors. The first one is fed with vegetable oil and methanol at a given ratio. Excess of methanol is removed after each reactor by partial evaporation. Esters and glycerin are then separated in a simple gravity settler. As transesterification routes goes with equilibrium reaction, glycerin interstage removal allows reaching higher conversion, close to thermodynamical limits. Glycerin outputs are gathered and the residual methanol is removed by evaporation. In order to obtain FAE at the European specifications, the last traces of methanol and glycerin have to be removed. The purification section of methyl ester from the second reactor and second decanter consists of a finishing methanol vaporization under vacuum followed by a final purification in an adsorber for removing the soluble glycerin. This adsorber uses neutralized ion-exchange resins which act as glycerin traps, once more enabling the elimination of the water washing step used in most homogeneous processes. Glycerin purity is routinely above $98 \%$, with average $0.5 \mathrm{wt} \%$ water content instead of a typical $13.5 \%$ water content of standard crude glycerin.

Fixed bed plug flow reactor (Fig. 15) were chosen for their ability to achieve better conversion level than stirred reactor. Reactor design ensure proper wetting of the catalyst throughout the complete bed height. Reactor operating 


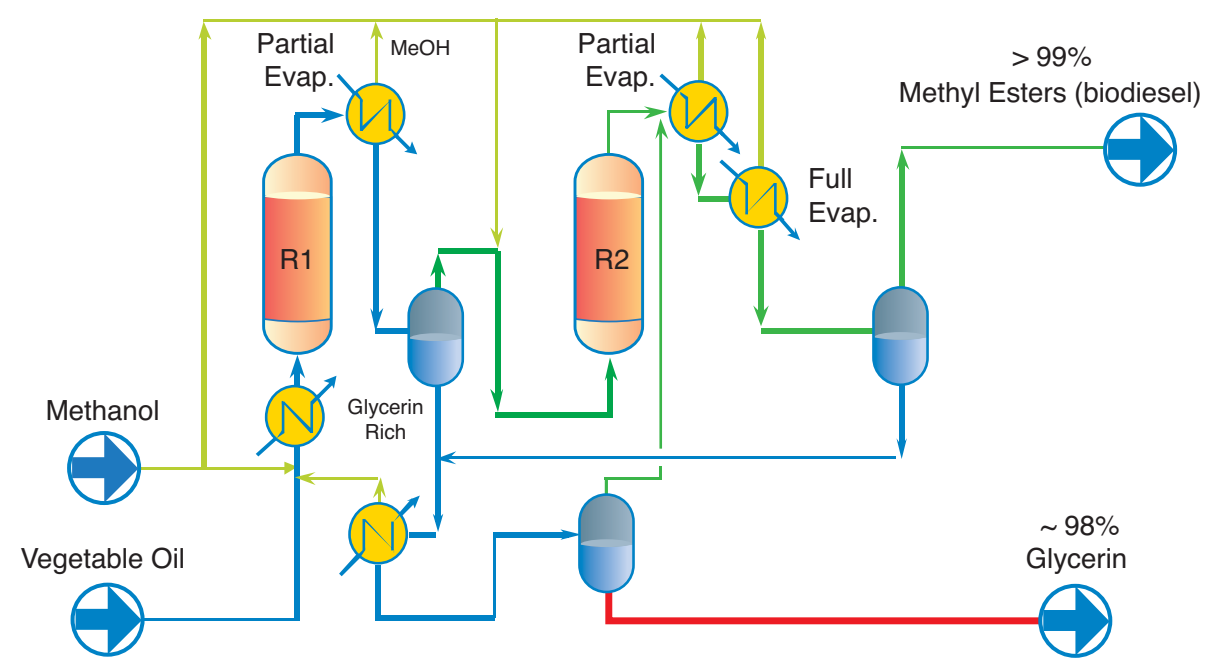

Figure 14

Simplified flow sheet of the new heterogeneous process, EsterFip-H.

conditions were chosen to have a single phase mixture between reactants and products and avoid glycerin phase separation which would limit reaction completeness through external diffusion limitation. Two beds are used to ensure a mid bed re-repartition of the fluids, ensuring proper distribution of liquid from bottom to top of the reactor.

No mechanical stirring before or in the reactor is used, fluid turbulence achieves continuous mixing. The catalyst was chosen to be able to handle high throughput and solvent effects of ester and methanol phases with no leaching of fines or metals within the process.

\section{Process Strengths and Weaknesses}

This new heterogeneous catalyst process offers the main following advantages:

- high FAE yield can be obtained, since there is no ester loss due to soap formation (FAME yield $=100 \%$ );

- the crude glycerol obtained is salt free and has a very high glycerol purity (>98\%), thus allowing new direct uses in chemical applications;

- only feed oil and methanol are consumed;

- there are no waste streams.

The reaction is performed at higher temperature and pressure than in homogeneous catalyst process, due to the lower activity of the solid catalyst.

\section{Heterogeneous Process Present Status}

The first plant in Sète (160 000 t/y) has been running for more than one year at high capacity with various vegetable oil sources including rapeseed, soy bean, blend with palm (blend only, FAE with full palm having a too high CFPP to be blended pure in diesel), sunflower. The catalyst has successfully converted the guaranteed oil amount and is still highly active and in excellent condition. Glycerin purity is also according to expectations with a purity of over $98 \%$.

The Perstorp plant (160 $000 \mathrm{t} / \mathrm{y}$ ) (Picture 3) started up successfully in the spring of 2007. There are 6 other heterogeneous Esterfip-H plants underway worldwide at various stage of design or construction.

\section{Heterogeneous Process Product Quality}

The first heterogeneous plant FAE met product quality requirement (Fig. 16) given in the EN 14214 FAE European specification, certified by independent analytical laboratory.

Products (Picture 4) delivered by the Esterfip-H process are shown above without further distillation or polishing steps.

\subsubsection{Glycerin Issues: Market, Valorization}

Glycerin is the co-product of FAE. Capacity expansion demonstrated for FAE will impact the glycerin market. Glycerin will eventually turn out to be a strength of FAE processes if some application is sufficient to absorb its mass production of 1/10th the FAE total production. Glycerin market is still split between 'crude' glycerin grade with $85 \%$ purity on average, salts water and organic material non soluble in glycerin also present, and pharmaceutical glycerin grade.

Glycerin is an old product and already has multiple usage (Fig. 17 - Glycerin market breakdown).

However, based on planned FAE expansion, new openings are found for glycerin. The reality of these new markets will depend on price [19], and quality (through the need of an adequate pretreatment) of glycerin [18].

New glycerin applications can be found as a downstream replacement of propylene:

- Glycerin can be further reacted into polyols. ADM announced in November 2005 (C\&EN Jan 2006) plans for 


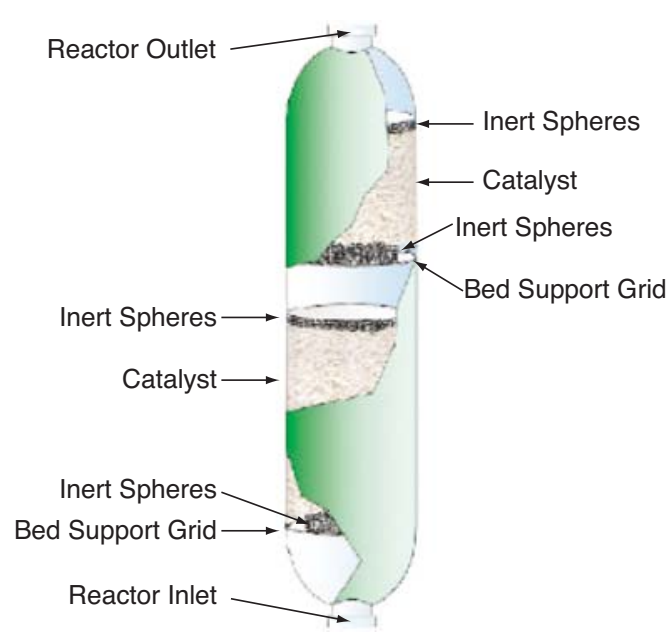

Figure 15

EsterFip-H reactor view.

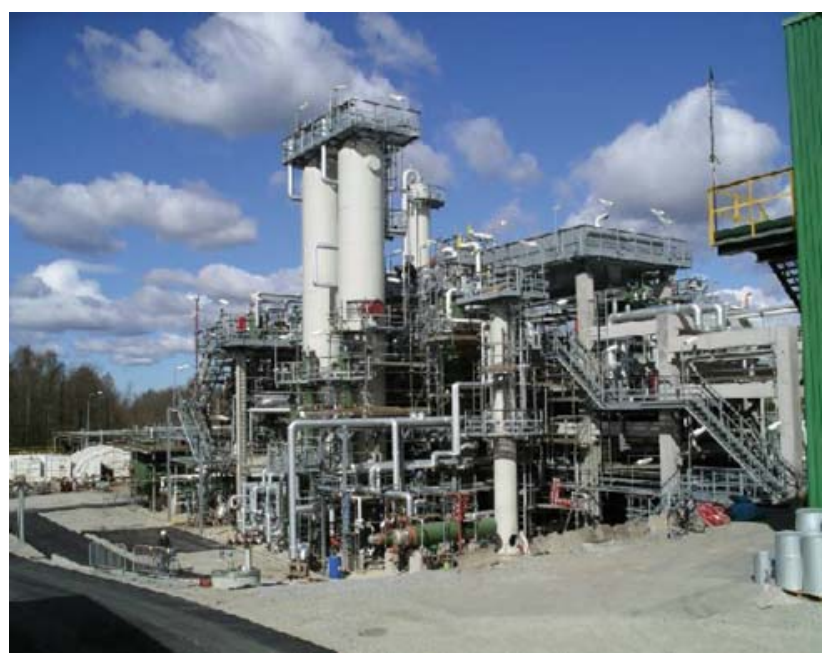

Picture 3

Perstorp 160000 tpy plant (Sweden).

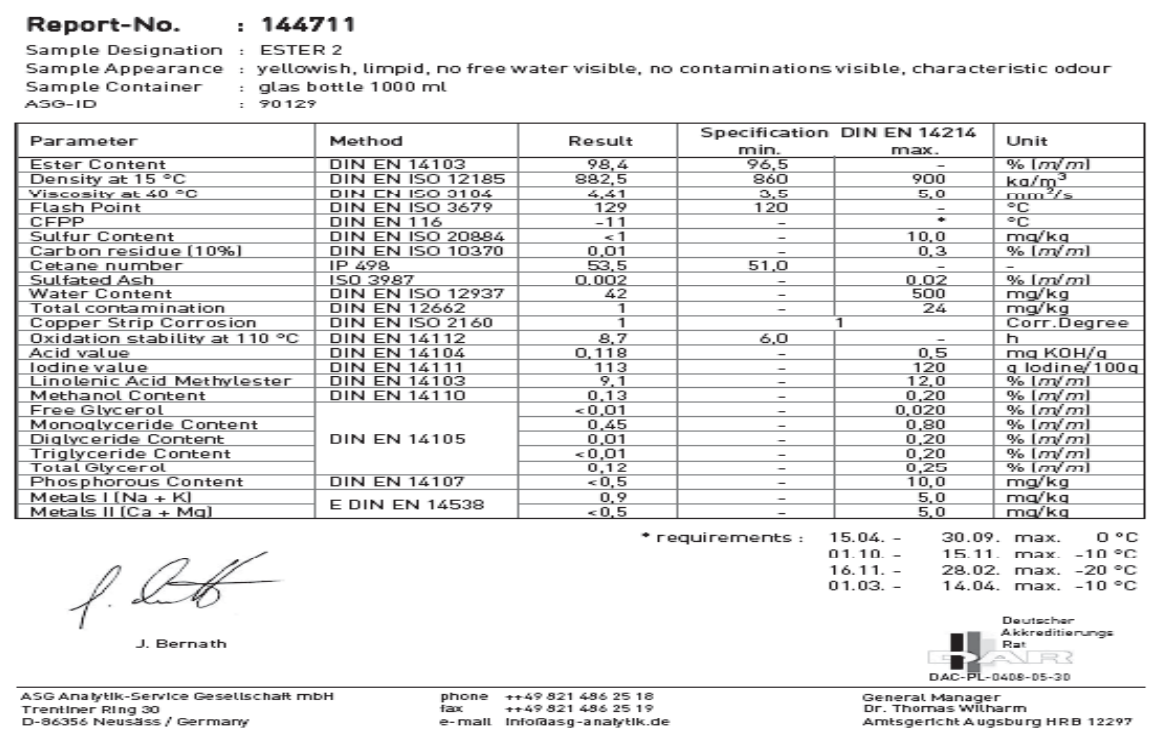

Figure 16

Heterogeneous FAE final quality.

a big facility to turn glycerin into propylene glycol and ethylene glycol.

Cargill and Ashland announced working on bio base propylene glycol from glycerin. More recently in 2007 Dow and Hunstmann did make similar announcement.

- Glycerin can be further reacted into epichlorhydrin. Solvay and Diester did make some announcement about the Epicerol process to use glycerin as feedstock instead of propylene. In C\&EN, 29 March, Dow did unveil the building of a chinese plant supporting the same kind of process.
- Usage of Glycerin to 1,3 propandiol through enzymatic reaction for a end usage as plasticizer, has been announced by MetEx French company recently.

- Use of glycerin for polyglycerol, acrolein manufacture is also reported [17].

- Use of glycerin for fuel additives manufacture like GTBE (glycerol ter-butyl ethers derived from isobutene mono, double or triple etherification of glycerol), either as gasoline additive or diesel additive when mixed with FAE, has been studied even if no commercial scale plant has been announced yet. 


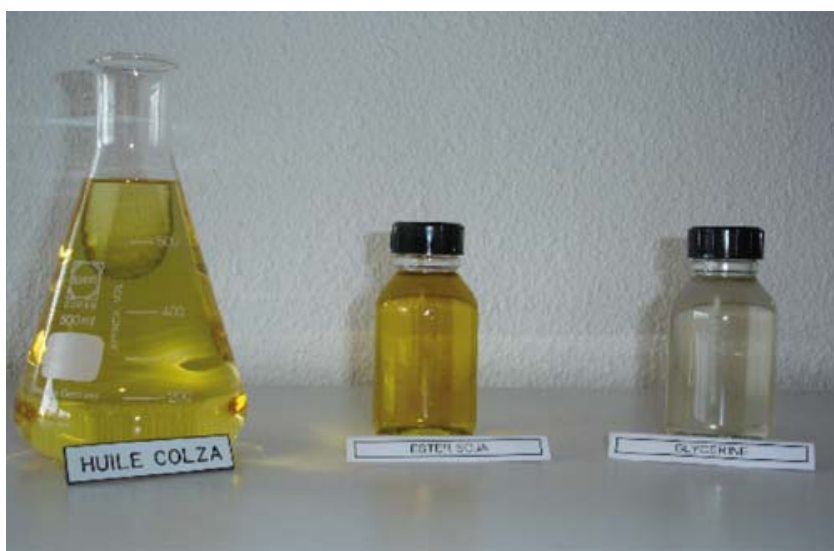

Picture 4

Heterogeneous FAE final product aspects.

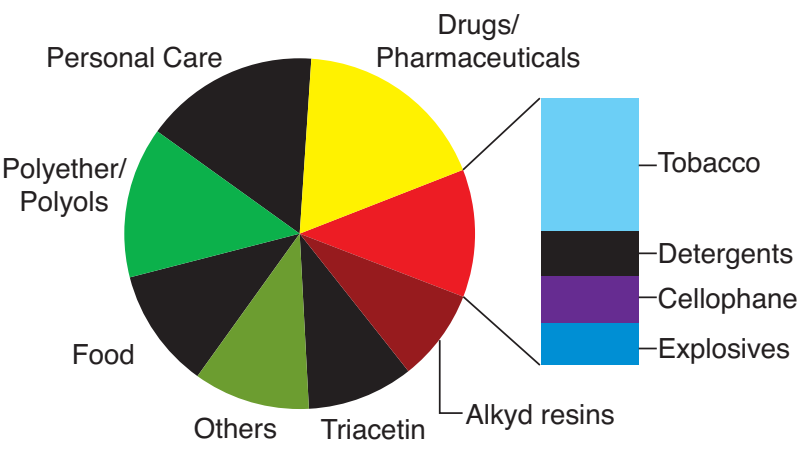

Source 2004: IFP, Novaol, US DOE

\section{Figure 17}

Glycerin market breakdown [17].

\subsubsection{Alternative Routes}

Replacement of fossil derived methanol by ethanol is an interesting objective:

- the ethyl ester would be $100 \%$ derived from biomass;

- this is a way to incorporate some ethanol in the diesel pool. This would help to fit the motor fuels consumption in Europe, where the gasoline/diesel usage ratio is low and still decreasing, which limits the market for ethanol used as a gasoline blending component.

However, this presents technical challenges for several reasons.

First, the reaction is slower: a higher amount of catalyst and/or higher temperatures are needed for ethyl esters production in order to balance the lower ethanol reactivity. Longer chain alcohol in a nucleophilic reaction will inevitably lead to this dramatic loss of activity upon stabilization of the oxygen in the alcohol molecule.

Second, ethanol is a better solvent than methanol for oil and ethyl esters. In the case of homogeneous catalysis, the higher solvent effect of ethanol induces more severe thermodynamic limitations for oil conversion, since glycerol produced is much more soluble in ethanolysis reaction mixture than in the case of methanolysis. On the contrary, in heterogeneous catalysis, the reaction mixture is monophasic with both methanol and ethanol: in that case, the thermodynamic limitations for oil conversion are roughly the same when using ethanol instead of methanol. However in all cases, ethanol acting as a co-solvent makes glycerol extraction from ethyl esters more complex and costly.

Finally, the well known affinity of ethanol for water and the possible formation of an azeotrope will make the necessary dehydration of the alcohol more complex.

\section{CONCLUSION}

Large opportunities are opening for the production of diesel oil from biomass. Vegetable oils will remain very important starting materials due to sustained high fossil oil price. Aside from the food for fuel issue and political and financial aspects, technology selection will play an important role in the future of FAE production by trans-esterification of vegetable oils. Biofuels processes must be environmentally friendly and meet the highest product quality standards to realize the full potential of biofuels. It will be necessary to develop new markets for the large amounts of glycerin coproduced to give trans-esterification units and integrated approach to link agricultural products, refinery fuels and chemical based product manufacture. To achieve this end, the choice of a heterogeneous process results in a greener process with quality products, superior yields and greater flexibility to adapt to future opportunities. Glycerin will eventually turn out to be a strength of FAE processes either through single application sufficient to absorb its mass production of $1 / 10$ th the FAE total production or through multiple smaller openings. In either way, accessing a quality grade glycerin directly out of the FAE process will give a strong plus in the long run.

\section{ACKNOWLEDGEMENT}

Authors would like to thanks X. Belin (IFP) for resourceful documentation, J. Ross (Axens NA), A. Forestiere for help in shaping this article.

\section{REFERENCES}

1 Stern R., Guibet J.C., Graille J. (1983) Revue Institut Français du Pétrole 38, 121-136. 
2 Bray R.G. (2004) Biodiesel Production, SRI Consulting.

3 Kijora C., Kupsch R.D. (1996) Fett-Lipid 98, 7-8, 240-245.

4 Bournay L., Casanave D., Delfort B., Hillion G., Chodorge J.A. (2005) Catal. Today 106, 190-192.

5 Stern R., Hillion G., Rouxel J.J. (1999) US Patent 5, 908, 946. 6 Hoang LeChien (1998) French Patent No. FR 2, 784, 116.

7 Mittelbach M., Remschmidt C. (2004) Biodiesel the Comprehensive Handbook, published by Martin Mittelbach, Austria, pp. 87-88.

8 Monnier J., Tourigny G., Soveran D.W., Wong A., Hogan E., Stumborg M. (1998) US Patent 5705722, Natural Resources Canada.

9 Ballerini D. (2006) Les biocarburants : état des lieux, perspectives et enjeux du développement, Ed. Technip, Paris, p. 226.

10 Hawkins C.S., Fuls J., Hugo F.J.C. (1983) Engine Durability Tests with SunFlower Oil in an Indirect Injection Diesel Engine, SAE 831357.

11 Skuda K.J. (1984) Vegetable Oil Or Diesel Fuel - A Flexible Option, SAE 840004.

12 Bernard F., Prieur A. (2006) Biofuel Market and Carbon Modeling to Analyse French BioFuel Policy, IFP School.
13 Van Walwijk M. (2005) BioFuels in France 1990-2005 PREMIA Report, TREN/04/FP6EN/S07.31083/503081.

14 Juergen Zeddies (2006) The Availability of Raw Material for the Production of BioFuels in Germany and in the EU-25, Univ. Hohenhein, Oct 2006.

15 Retzlaff K. (2006) The German Biodiesel Market Recent Developments, IEA Task 39, VDB - Germany Biofuels Industry Association.

16 Biofuels barometer, EurObserver ER 2007 No. 179.

17 Pagliario M. (2007) From Glycerol to Value Added Product, Angew. Chem. Int. Edit. 46, 4434, 4440.

18 Okonek D. (2007) Practical Short Course on Biodiesel and Industrial Applications of Vegetable Oils, August 19-22.

19 Heming M.HBI, Onidol S. Claude (2006) Glycerol, une croissance de la demande attendue pour 2008, InfoChimieMagazine No. 474, Septembre/Octobre 2006.

Final manuscript received in May 2008 Published online in August 2008 